\title{
Presupuestos teóricos, dogmática jurídica e interpretación constitucional de los derechos de las personas extranjeras en España*
}

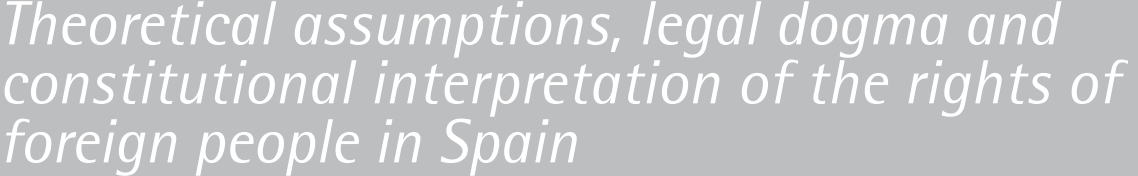

\section{Marco Aparicio Wilhelmi**}

\section{RESUMEN}

El presente trabajo propone un abordaje crítico de la interpretación constitucional tomando como objeto el régimen de los derechos de las personas extranjeras en España. A partir de la distinción entre dogmática jurídica, presupuestos teóricos y postulados politicos o morales, se avanza en el planteamiento de los requisitos para una dogmática jurídica crítica. Tras ello, el texto hace un somero repaso de los elementos centrales de la jurisprudencia constitucional sobre los derechos de las personas extranjeras, hasta llegar a la STC 236/2007. Este repaso concluye con una critica al uso del principio de dignidad como criterio central de valoración del alcance de la potestad del legislador para introducir restricciones distintas de las planteadas para los nacionales. A continuación, se identifican los presupuestos teóricos que conducen a dicha línea interpretativa para, después, proponer una aproximación distinta, contrahegémonica. Finalmente, con base en tales presupuestos teóricos, se propone partir del principio de igualdad como criterio ordenador de la comprensión de los derechos constitucionales, sean cuales sean sus titulares.

PALABRAS CLAVE: Interpretación constitucional, derechos fundamentales, Constitución española, extranjería.

\begin{abstract}
This work proposes a critical approach to constitutional interpretation taking as an object the regime of the rights of foreign people in Spain. Starting from the distinction of legal dogma, theoretical assumptions and political or moral postulates, there is progress in the approach of the necessary requirements for a critical legal dogma. The text then makes a review of the central elements of Constitutional jurisprudence on the rights of foreigners persons, until reaching the STC 236/2007. This review concludes with a critic on the use of the principle of dignity as a central criterion for the assessment of the scope of the authority of legislature to introduce restrictions other than those raised for nationals. Then, the theoretical assumptions are identified that lead to this line of interpretation; and thereby, propose a different approach; counterhegemonic. Finally, based on such theoretical assumptions, it is suggested to start from the principle of equality as an organizing criterion from the understanding of constitutional rights, whatever identity the persons have.
\end{abstract}

KEY WORDS: Constitutional interpretation, Fundamental rights, Spanish Constitution, Immigration Law.

\footnotetext{
* Recibido: 31 de julio de 2015. Aprobado: 8 de septiembre de 2015.

**Profesor en la Universidad de Girona, España. (marco.aparicio@udg.edu)
} 


\section{SUMARIO}

1. La "verdad" jurídica y sus condiciones subyacentes

2. Los derechos de las personas extranjeras según la dogmática constitucional

2.1 Introducción

2.2 Los derechos de las personas extranjeras según la dogmática constitucional

2.3 Punto (actual) de llegada de la dogmática constitucional: la sTc 236/2007

3. Una aproximación crítica: la igualdad (o igual dignidad) como criterio ordenador

3.1 Introducción

3.2 La dignidad como artilugio: la opción por la jerarquización entre derechos

3.3 Los presupuestos teóricos al descubierto

3.4 Una propuesta contrahegemónica

3.5 La igualdad como punto de partida (y de llegada)

4. A modo de epílogo: la libre movilidad como presupuesto

\section{La "verdad" jurídica y sus condiciones subyacentes}

En su conocida obra Las palabras y las cosas, ${ }^{1}$ Michel Foucault analiza el modo en que se van construyendo, en distintos periodos históricos, una serie de presupuestos conceptuales que configuran lo aceptable, la óptica o el orden bajo el cual se piensan las cosas. Se trata de las condiciones subyacentes de la verdad; una determinada verdad que logra mostrarse como patrón explicativo. Desde el Renacimiento aparece como ciencia, como verdad científica; no fue el resultado del progreso de la razón sino, más bien, el fruto de un unas reglas propias de cada época, y que responden, en su historicidad, a relaciones de poder.

En el terreno jurídico, podríamos también adoptar este planteamiento: las cosas, el derecho, son nombradas y configuradas a partir de palabras que surgen de condiciones subyacentes. Así se configura la dogmática jurídica, que se reclama como verdad científica. Si bien esto mismo sucede en cualquier disciplina de las ciencias humanas, incluidas las ciencias sociales, lo cierto es que en el ámbito jurídico la dogmática se puede identificar con mayor certeza porque el mismo sistema jurídico objeto del estudio establece quiénes son los máximos hacedores de dogmática. En efecto, cada ordenamiento jurídico establece fuentes encargadas de decir derecho, de hacer jurisprudencia, a partir de un sistema jurisdiccional organizado de manera jerárquica.

Así, los sistemas jurídicos, al menos los de tradición liberal, establecen el carácter vinculante de la jurisprudencia de sus máximas instancias jurisdic-

${ }^{1}$ Foucault, Mıchel. Las palabras y las cosas. Una arqueología de las ciencias humanas, Siglo XXI, Madrid, 1998. 
cionales: Tribunal Supremo y, alli donde existe, Tribunal Constitucional. Tales instancias crean el dogma científico, revelan la "verdad" jurídica. Se trata de un dogma, un discurso incontestable, que el resto del sistema jurisdiccional debe aceptar, aunque, como sabemos, puedan llegar a modificarlo, de manera suficientemente razonada, quienes lo han construido.

A la hora de acercarnos a la comprensión del derecho, podemos optar por limitarnos a su dimensión dogmática, esto es, a una dimensión descriptiva del sentido dado a las normas. Se puede también tratar de identificar (de manera igualmente descriptiva) las herramientas metodológicas empleadas. Esta aproximación es, sin duda, la más habitual. Incluso (o sobre todo) en el ámbito académico, donde la formación del jurista suele centrarse en la dimensión dogmática.

Nuestros sistemas jurídicos, y la dogmática que los conforma y los hace aplicativos, dan respuestas cuando menos insuficientes al reto de la salvaguarda y efectividad de los derechos, individuales y colectivos, como presupuestos de una convivencia democrática incluyente. Si estamos de acuerdo con la anterior aseveración, un siguiente paso nos podría llevar a cuestionar el modo en que resulta habitual acercarnos al estudio del derecho: la mencionada aproximación dogmática, acrítica.

La finalidad consistiría en elaborar una dogmática crítica, contrahegemónica si se quiere, con aspiraciones, eso sí, de devenir influyente, hegemónica incluso. Si pretendemos que tal dogmática sea verdaderamente crítica, no bastará con proponer otra lectura, otro discurso, ni tan siquiera otro método, si la propuesta se hace en términos igualmente dogmáticos; es decir, sin desvelar las herramientas teóricas de las cuales se parte ni situar los planteamientos morales o políticos que fundamentan la aproximación.

Quizás sirva la siguiente imagen. Podríamos hablar de un triángulo equilátero cuyos vértices son los siguientes: a) dimensión política o moral; b) dimensión teórica; c) dimensión dogmática. La comprensión del derecho, y su defensa como herramienta de regulación, de abordaje prescriptivo de las relaciones humanas, sólo puede ser crítica, y hacer frente a la dogmática jurídica (hegemónica), si es capaz de desvelar que cualquier interpretación jurídica pone en interrelación los tres vértices.

La operación, por tanto, sería la siguiente: si rechazamos el resultado que se obtiene a partir de una determinada interpretación de la norma (en términos de insuficiencia garantista de determinados derechos, por ejemplo), la primera tarea supone develar el modo en que dicha interpretación se construye (la interrelación de los tres vértices) para después explorar la posibilidad de construir otra interpretación capaz de dotar de otro sentido, de construir otra 
"verdad", que no es más que una proposición más convincente, mejor trabada, más coherente en la elección y uso de las herramientas teóricas y en el modo en que se obtiene el resultado interpretativo. Este intento, a buen seguro, se hallará motivado por una distinta concepción política o moral que no tiene por qué ocultarse: no debe ser vista como sacrilegio frente al dogma, sino como elemento inescindible de cualquier construcción dogmática.

Hay quienes verían en esta propuesta una apelación al llamado uso alternativo del derecho. Quizás sea más sencillo afirmar que se trata de tomarse el derecho en serio. Dado que existe una pretensión de sistematicidad y coherencia, necesariamente debemos aproximarnos al derecho desde una perspectiva crítica, pues sólo así se construye conocimiento científico. Entendemos este último no como realización de una pretendida objetividad, sino como voluntad de dotarnos de herramientas explicativas rigurosas y con utilidad social.

No obstante, debemos ser conscientes de las limitaciones del método crítico en términos de su incidencia en los procesos de transformación social. a) Porque se refiere a normas ya dadas, enunciados normativos resultado de relaciones de poder profundamente asimétricas; b) porque las mencionadas condiciones subyacentes de la verdad hacen que la disputa por el sentido de las palabras (de las cosas), sea en sí misma desequilibrada, de manera que cualquier aproximación crítica tendrá que enfrentarse con el peso de la normalidad (lo posible, lo razonable); c) porque incluso si logra influir pronunciamientos jurisdiccionales, no siempre el éxito en batallas jurídicas empuja cambios sociales, sino que, paradójicamente, en ocasiones genera un efecto legitimador del sistema en su conjunto, de la "normalidad".

Sea como sea, dar forma a una aproximación crítica al derecho es una labor cada vez más necesaria, por cuanto, al menos, puede servir para poner de manifiesto las inconsistencias en que a menudo incurre la dogmática jurídica, así como la existencia de otras epistemes posibles y deseables. Esta tarea es la que se pretende abordar, de modo necesariamente limitado, en este escrito. Concretamente, como a continuación veremos, el trabajo propone un abordaje crítico de la interpretación constitucional tomando como objeto el régimen de los derechos de las personas extranjeras en España.

La hipótesis de partida se recoge en los siguientes planteamientos: cualquier interpretación jurídica está asentada en una serie de presupuestos teóricos y en posicionamientos políticos y morales del intérprete. Resulta posible construir una dogmática jurídica crítica a partir del cuestionamiento de los presupuestos teóricos hegemónicos, encaminada a consolidar una perspectiva garantista, amplia e inclusiva, en materia de derechos constitucionales. En el caso de los derechos de las personas migrantes en España, esta operación pasa 
por cuestionar el uso interesado que el Tribunal Constitucional ha realizado del principio de dignidad para sustentar el eje interpretativo en el principio de igualdad.

\section{Los derechos de las personas extranjeras según la dogmática constitucional}

\subsection{Introducción}

Por desgracia, son muchos los ámbitos en los que urge promover una dogmática jurídica crítica. En el plano constitucional, y concretamente en el de los derechos, uno de los terrenos más necesitados lo constituyen, sin duda, los derechos sociales, derechos tradicionalmente debilitados, desconstitucionalizados incluso. Pero también aspectos referidos a los llamados derechos de libertad, como la libertad de expresión, o de reunión y manifestación, afectados por las tenencias que marca el populismo punitivo de orden securitario.

Ahora bien, para el caso español, una de las realidades que desde su propia configuración han sufrido en mayor medida el peso de una dogmática jurídica liberticida ha sido el de la extranjería, esto es, el de la comprensión del régimen de ejercicio de los derechos por parte de las personas extranjeras. Sucede que en este ámbito se ha logrado imponer un sentido común en virtud del cual nos hallaríamos ante un régimen atravesado por la lógica de la excepcionalidad. Pautas jurídicas (en la propia norma o en su dimensión aplicativa) exigibles en condiciones ordinarias podrían relajarse o directamente suprimirse cuando se refieren a extranjeros.

Es el caso de los principios de seguridad jurídica e interdicción de la arbitrariedad, violentados tanto en la propia norma (mediante conceptos jurídicos indeterminados que abonan un terreno de ambigüedad aplicativa), como en su aplicación (claramente en el control fronterizo, o en el continuo cambio de criterios para la concesión de los visados, en las renovaciones a las autorizaciones de residencia y trabajo, en el reagrupamiento familiar). También es el caso, evidentemente, del régimen de los centros de internamiento y de otras situaciones, como la de las personas sobre quienes recae una orden de expulsión y sin embargo no son expulsables al no existir convenios con los países de origen.

En definitiva, la extranjería en su conjunto determina un inaceptable grado de precariedad de las condiciones de ejercicio de derechos constitucionalmente consagrados, tanto de quienes se encuentran en situación de regularidad administrativa como, especialmente, de quienes se hallan en situación irregular. 
Es importante señalar que la normativa de extranjería ha sido, y continúa siendo, pieza fundamental de un proyecto de convivencia social determinado. Hablamos por tanto de una serie de opciones políticas que afectan al conjunto de la sociedad y no sólo a las personas inmigradas. En este sentido, es evidente que las dificultades de acceso y permanencia en el territorio y, en general, las restricciones a los derechos de personas inmigrantes tienen efectos no sólo dentro de este colectivo, sino respecto de todas las personas, especialmente aquéllas que han ido situadas en condiciones de mayor vulnerabilidad. La precariedad, la explotación y la accidentalidad laborales, tanto en el ámbito de la economía regular como de la economía sumergida, no son patrimonio exclusivo de inmigrantes; son situaciones con una dinámica expansiva que acaban configurando el modelo de relaciones laborales en su conjunto y, con él, un modelo de desarrollo económico y social, unas prioridades y unos objetivos específicos.

Por estas razones, centrar nuestra atención en el régimen de extranjería es responder a la apelación hecha en su día por Walter Benjamin: "La tradición de los oprimidos nos enseña que el estado de excepción en el que vivimos es la regla”. ${ }^{2}$

\subsection{Los derechos de las personas extranjeras según la dogmática constitucional}

La Constitución española de 1978 contiene una previsión general sobre el régimen de los derechos de las personas extranjeras. Se trata del artículo 13, que en sus dos primeros apartados dispone:

1. Los extranjeros gozarán en España de las libertades públicas que garantiza el presente Título en los términos que establezcan los tratados y la ley.

2. Solamente los españoles serán titulares de los derechos reconocidos en el artículo 23, salvo lo que, atendiendo a criterios de reciprocidad, pueda establecerse por tratado o ley para el derecho de sufragio activo y pasivo en las elecciones municipales.

De una primera lectura podriamos concluir que, en materia de derechos, la Constitución española no establece un principio de necesaria equiparación entre nacionales y extranjeros, pero tampoco permite que la ley condicione

${ }^{2}$ Benjamin, Walter. Tesis sobre la historia y otros fragmentos, Itaca, México, 2008. 
libremente el ejercicio de los derechos y libertades de los extranjeros. Se reconoce un "principio de equiparación limitada" que toma como punto de partida la dignidad de la persona (artículo 10.1) y el reconocimiento internacional de los derechos humanos (artículo 10.2) y el hecho de que, de acuerdo con el artículo 13, todos los derechos constitucionales (menos el derecho de sufragio activo y pasivo, a excepción de las elecciones locales) son también derechos de las personas extranjeras.

Así pues, la nacionalidad de la persona puede ser, en España, en ciertas ocasiones, un aspecto suficientemente relevante para diferenciar las condiciones en que se puede ejercer un determinado derecho. De todas formas, el criterio de la nacionalidad no podrá considerarse en relación con todos los derechos ya que el Tribunal Constitucional (тс, en adelante) ha afirmado con claridad que hay una serie de derechos sobre los cuales no se puede diferenciar en ningún caso entre españoles y extranjeros. Se trata de los derechos que, de acuerdo con la doctrina, deben considerarse esenciales para garantizar a todo individuo el respeto de su dignidad humana, los derechos "más vinculados a la persona por el mismo hecho de serlo", derechos humanos universalmente protegidos (derecho a la vida, a la integridad física y moral, a la intimidad personal, al honor y a la propia imagen, a la libertad personal, a la libertad ideológica, religiosa y de culto).

De este modo, el Tc distinguiría entre tipos de derechos: a) los derechos cuya titularidad está excluida a los extranjeros (derecho de sufragio activo y pasivo, excepto en elecciones locales, que puede ser reconocido si existe reciprocidad, de acuerdo con lo que dispone el artículo 13.2); b) los derechos en los cuales en ningún caso cabe un régimen de ejercicio diferenciado entre españoles y extranjeros; c) los derechos en los cuales caben distinciones si el legislador lo considera necesario.

Este tercer grupo de derechos serían, debemos deducir, aquellos menos vinculados con el principio de dignidad; por esta razón, en palabras del тc, podrán ser "atemperados". ${ }^{3}$ Es decir, podrán establecerse condicionantes especiales para su ejercicio por parte de personas extranjeras. Ahora bien, estos condicionantes no serían ilimitados o arbitrarios, puesto que, en todo caso, se trata de derechos reconocidos a los extranjeros (según reza el artículo 13.1). Esto implica que el legislador debe respetar un contenido mínimo de cada uno de ellos.

Concretamente, el Tc ha afirmado que "no se puede estimar aquel precepto [artículo 13.1] permitiendo que el legislador configure libremente el contenido mismo del derecho, cuando éste ya haya venido reconocido por la Constitución

${ }^{3}$ STC 99/1985, FJ 2. 
directamente a los extranjeros". ${ }^{4}$ Debe igualmente destacarse la contundencia con la que se expresa la STC 94/1993, que nos recuerda que todos los derechos del título I, a excepción de los que marca el artículo 13.2, vienen directamente reconocidos a las personas extranjeras.

¿Hasta dónde llega el límite que deberá respetar el legislador? El тс no ofrece una respuesta genérica, una especie de definición general de contenido mínimo; inevitablemente hay que abordar la cuestión derecho por derecho, según la naturaleza de cada uno. Merece la pena destacar que el тс ha insistido en este razonamiento, independientemente del modo en que los derechos vengan reconocidos en la Constitución (esto es, al margen de que literalmente se refieran sólo a "los españoles").

Esta jurisprudencia, aunque ha experimentado ciertos vaivenes, aparece desde los primeros tiempos. Para empezar, se encuentra en la STC 107/1984, donde se dilucidaba si la exigencia a los extranjeros del permiso de residencia como requisito para la validez de un contrato de trabajo podía llegar a vulnerar el principio de igualdad. En este pronunciamiento, el Tc optó por excluir como parámetro de interpretación el artículo 14 (cláusula antidiscriminatoria).

Lo hace también en la primera sentencia importante, la STC 115/1987 que resolvía el recurso de inconstitucionalidad presentado contra la primera Ley de Extranjería (Ley Orgánica 7/1985). Por medio de esta resolución, el Tc rechaza plantearse la diferencia de trato entre españoles y extranjeros como un asunto vinculado a la justificación del trato desigual, para limitarse a analizar caso por caso si el régimen de ejercicio regulado afecta o no al contenido mínimo del derecho. Así, en el caso del derecho de asociación, la desigualdad es considerada inconstitucional no por afectar al artículo 14, sino por no respetar el contenido irrenunciable del derecho: el problema "no es el de si es posible aquí esta diferencia de trato en el ejercicio del derecho entre los extranjeros y los españoles, sino si el legislador ha respetado el contenido preceptivo e imperativo que establece el artículo 21.1 de la Constitución, también para los extranjeros".

La misma línea jurisprudencial se sigue en la STC 144/1990 (vulneración de la tutela judicial y la libertad personal en un caso de internamiento de extranjeros). La sтc 94/1993, donde analiza la constitucionalidad de una orden de expulsión respecto del contenido del derecho a la libre circulación; la sтс 95/2000, donde se aborda un caso de acceso a prestaciones sanitarias a través de la garantía del contenido mínimo de la tutela judicial efectiva; la STc 95/2003, donde resuelve un recurso de inconstitucionalidad referido a la

\footnotetext{
${ }^{4}$ STC $115 / 1987$ FJ 3.
} 
exclusión de los extranjeros en situación irregular del derecho a la asistencia jurídica gratuita.

\subsection{Punto (actual) de llegada de la dogmática constitucional: la STC 236/2007}

Tras el recorrido descrito, llegamos a la STC 236/2007, fruto del recurso de inconstitucionalidad interpuesto contra la reforma de la Ley Orgánica 4/2000 (la segunda Ley de Extranjería, tras la de 1985) operada por la Ley Orgánica 8/2000. ${ }^{5}$ En esta sentencia, el Tribunal Constitucional ratifica el elemento central de su aproximación al artículo 13: el legislador podrá afectar en mayor o menor medida el modo en que los extranjeros ejercen sus derechos constitucionales en función de la relación que cada derecho tenga con el principio de dignidad.

Como nos explica Viana, ese grado de conexión se debe deducir identificando -en abstracto- el núcleo esencial del derecho y buscando la conexión con la dignidad que a él reconozcan los tratados internacionales. Esta metodología tendría, señala la misma autora, tres problemas: "el primero consiste en que trae consigo un obstáculo práctico que consiste en que ningún tratado internacional utiliza el criterio del nivel de vinculación con la dignidad; el segundo es que está construida sobre un error de lógica jurídica, pues los derechos tienen, todos, una única relación posible con la dignidad: una dependencia necesaria; y el tercero es que supone una interpretación que no consulta los criterios que la propia Constitución impone y que, por eso mismo, no tiene efectos útiles". ${ }^{6}$

Esta línea interpretativa es llevada por la STc 236/2007 al punto de identificar una categoría de derechos que "por su propia naturaleza son incompatibles con la situación de irregularidad”. De esta manera, respecto de los mismos el legislador debería excluir a las personas en situación de irregularidad estableciendo como necesaria condición de ejercicio del derecho la regularidad administrativa del sujeto titular. Uno de los problemas es que el Tribunal Constitucional sitúa dicha contundente categorización en un plano abstracto, sin concreción alguna de los derechos implicados. Veamos cómo desarrolla su argumento el тc en este

\footnotetext{
${ }^{5}$ Se trata de la primera reforma de la vigente ley de extranjeria, impulsada por el gobierno del Partido Popular el mismo año de la aprobación de la ley. Posteriormente fueron realizadas más reformas que, fruto de ello, hacen que su redactado actual diste mucho del inicial. Entre tales reformas, destacan las operadas por las Leyes Orgánicas $11 / 2003,14 / 2003$ y $2 / 2009$.

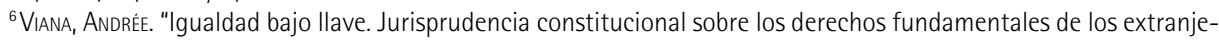
ros", en Andrée Viana, A. (Coord.), Repensar la pluralidad, Tirant lo Blanch, Valencia, 2009, pp. 303-339.
} 
tan trascendental aspecto. Concretamente, se trata del fJ 4 de la mencionada sentencia, que se inicia de la siguiente forma:

El legislador contemplado en el art. 13 CE se encuentra asimismo limitado al regular aquellos derechos que, según hemos declarado, "la Constitución reconoce directamente a los extranjeros" (STC 115/1987, de 7 de julio, FJ 2), refiriéndonos en concreto a los derechos de reunión y asociación. Ello implica, de entrada, que el legislador no puede negar tales derechos a los extranjeros, aunque sí puede establecer "condicionamientos adicionales" respecto a su ejercicio por parte de aquéllos, si bien "ha de respetar, en todo caso, las prescripciones constitucionales, pues no puede estimarse aquel precepto [artículo 13.1 $\mathrm{CE}$ ] permitiendo que el legislador configure libremente el contenido mismo del derecho, cuando éste haya venido reconocido por la Constitución directamente a los extranjeros. Una cosa es, en efecto, autorizar diferencias de tratamiento entre españoles y extranjeros, y otra entender esa autorización como una posibilidad de legislar al respecto sin tener en cuenta los mandatos constitucionales". ${ }^{7}$

Una vez identificados los derechos de reunión y de asociación como derechos "atemperables", aunque con límites, por el legislador, el Tribunal Constitucional prosigue afirmando que existen otros derechos donde el margen del legislador es aún mayor:

El legislador goza, en cambio, de mayor libertad al regular los "derechos de los que serán titulares los extranjeros en la medida y condiciones que se establezcan en los Tratados y las Leyes" (Sтc 107/1984, de 23 de noviembre, Fu 4), o dicho de otro modo, de aquellos derechos que no son atribuidos directamente por la Constitución a los extranjeros pero que el legislador puede extender a los no nacionales "aunque no sea necesariamente en idénticos términos que los españoles” (STC 94/1993, de 22 de marzo, FJ 3).

Y prosigue el тс especificando derechos que se hallarían en esta categoría de mayor debilidad frente a las restricciones que el legislador quiera imponer: 
De nuestra jurisprudencia se deduce que éste sería el régimen jurídico de derechos tales como el derecho al trabajo (STc 107/1984, de 23 de noviembre, FJ 4), el derecho a la salud (STC 95/2000, de 10 de abril, FJ 3), el derecho a percibir una prestación de desempleo (sTC 130/1995, de 11 de septiembre, FJ 2), y también con matizaciones el derecho de residencia y desplazamiento en España. ${ }^{8}$

Finalmente, se atreve a dar un paso más para señalar que existirían unos derechos de los cuales se puede excluir al colectivo de personas en situación de irregularidad:

El legislador puede tomar en consideración el dato de su situación legal y administrativa en España, y exigir a los extranjeros la autorización de su estancia o residencia como presupuesto para el ejercicio de algunos derechos constitucionales que por su propia naturaleza hacen imprescindible el cumplimiento de los requisitos que la misma ley establece para entrar y permanecer en territorio español. Esta opción no es constitucionalmente ilegítima [...] El incumplimiento de aquellos requisitos legales impide a los extranjeros el ejercicio de determinados derechos o contenidos de los mismos que por su propia naturaleza son incompatibles con la situación de irregularidad.

Salta a la vista la inconsistencia de afirmar que existen derechos incompatibles con la irregularidad. En cambio, afirma que su exclusión "no es constitucionalmente ilegitima”. En efecto, si son incompatibles no es que no sea ilegítima la exclusión de los irregulares, sino que es obligada. Pero al margen de lo anterior, como ya fue advertido, el problema es que, "en la sentencia no hay ningún caso en el que se encuentre una aplicación práctica para esta novedad, por lo que no se puede saber a qué se refiere el Tribunal". Siguiendo con Viana, se trataría de un planteamiento que puede "sugerir efectos probablemente incompatibles con el sistema de fuentes de un Estado Constitucional, como el de imputar a la naturaleza jurídica de un derecho constitucional su inferioridad frente a normas de naturaleza administrativa". 9

Sea como sea, mediante la STC 236/2007, si bien el Tc considera inconstitucional la exclusión total de los extranjeros en situación irregular del derecho de reunión y de asociación (como también de los de sindicación y huelga), al

\footnotetext{
${ }^{8}$ SSTC 94/1993, de 22 de marzo, fJ 3; 242/1994, de 20 de julio, FJ 4; 24/2000, de 31 de enero, FJ 4.

${ }^{9}$ Viana, AndRÉE. Op. cit.
} 
mismo tiempo deja la puerta abierta a otro tipo de restricciones sin definir su posible alcance y ratificando una más que cuestionable jerarquización entre derechos en función de su pretendidamente diferenciada vinculación al principio de dignidad de la persona.

\section{Una aproximación crítica: la igualdad (o igual dignidad) como criterio ordenador}

\subsection{Introducción}

Hay un constante ruido de fondo en la jurisprudencia del тс, amplificado en la última sentencia comentada: el rechazo mostrado por el Alto Tribunal a fijar la comprensión de los derechos constitucionales en su estrecha vinculación con el principio de igualdad, sin exclusiones. Se trata de un ruido generado por el propio Tribunal Constitucional que muestra en sus argumentaciones contradicciones notorias. Por ejemplo, en el mismo fu 4 de la sentencia recién comentada, el Tribunal Constitucional rechaza el uso del criterio de la igualdad, pero al mismo tiempo señala la necesidad de seguir los pasos que el principio de igualdad exige a la hora de determinar cuándo un tratamiento diferenciado resulta aceptable y cuándo no. En efecto, al configurar el margen de actuación del legislador, el Tribunal Constitucional señala:

La libertad del legislador se ve asimismo restringida por cuanto las condiciones de ejercicio que establezca respecto de los derechos y libertades de los extranjeros en España sólo serán constitucionalmente válidas si, respetando su contenido esencial (art. 53.1 CE), se dirigen a preservar otros derechos, bienes o intereses constitucionalmente protegidos y guardan adecuada proporcionalidad con la finalidad perseguida.

Salta a la vista que, sin especificarlo, el Tribunal recurre al test de razonabilidad. Si bien es cierto que dicho test puede aplicarse de manera general como criterio para enjuiciar restricciones a los derechos, no cabe duda que su lugar de aplicación más fructífero, tanto en la jurisprudencia del Tribunal Constitucional como del Tribunal Europeo de Derechos Humanos, es el referido al alcance de las cláusulas antidiscriminatorias. Por esta razón, sorprende que el тc exija los requisitos de la finalidad constitucionalmente admisible y de proporcionalidad (además, se entiende, del carácter racional de la medida) inmediatamente después de haber optado por separarse explícitamente del principio de igualdad, que sería sustituido por una cuestionable concepción de la dignidad. 


\subsection{La dignidad como artilugio: la opción por la jerarquización entre derechos}

Decíamos al principio que para poder avanzar hacia una dogmática crítica resulta necesario poner en relación un triángulo en el cual además aparezcan los presupuestos teóricos y las motivaciones políticas o morales. Llega el momento de hacerlo respecto del planteamiento del Tribunal Constitucional en materia de derechos de las personas extranjeras.

La jurisprudencia constitucional, según hemos visto, ha recurrido a la dignidad y ha optado por crear un extraño ingenio, el dignitómetro, que permitiría medir la distancia que cada uno de los derechos constitucionales tiene con el principio de dignidad. Tal distancia nos daría la medida del margen de actuación del legislador a la hora de establecer restricciones al ejercicio de los derechos por parte de los extranjeros.

Pues bien, debe decirse que no existe ningún anclaje constitucional mínimamente sólido para esta construcción. Como es sabido, el título I constitucional se inicia con el principio de dignidad contenido en el artículo 10.1, como preámbulo de todo el título (se halla dispuesto de manera previa a los distintos capítulos en él contenidos). Por esta razón, la dignidad se refiere al conjunto de derechos regulados en los siguientes capítulos, sin distinción.

Una posible salida que hubiera tenido el tc para establecer jerarquías entre derechos como paso previo a la cuantificación del margen con el que el legislador puede afectar los derechos de los extranjeros, hubiera sido referirse al grado de protección jurisdiccional. Dado que según el artículo 53 hay derechos protegidos de manera especial (los de la sección 1 del capítulo segundo, más el artículo 14), podría llegar a entenderse que se trata de derechos considerados más importantes. Siendo así, respecto de los mismos no cabría distinción entre españoles y extranjeros, algo que sí se podría hacer respecto de los derechos de la sección 2 del capítulo segundo (artículos 30 en adelante) o, incluso de manera más intensa, respecto a los del capítulo tercero, que recoge derechos como el derecho a la salud o a una vivienda digna.

El problema de esta línea interpretativa, que a diferencia de la anterior sí tendría un cierto asiento constitucional, es que entonces deberían incluirse como derechos no atemperables, además del propio artículo 14 (principio de igualdad), el derecho a la libre circulación (artículo 19), eje imprescindible, junto con el derecho al trabajo, del régimen de extranjería. En otras palabras: si no se pudieran establecer diferencias entre nacionales y extranjeros en relación con la libertad de circulación y residencia, dejaría de existir la extranjería. La razón del Tribunal Constitucional para no adoptar esta solución parece, por tanto, entendible. 
Así las cosas, el curioso artilugio metodológico empleado por el тс genera una inconsistente jerarquización de derechos que debe ser rechazada. Tras ella, se sitúa una serie de apriorismos, aparatos teóricos ocultos que parten, además, de una determinada concepción política. Esta concepción podría sintetizarse en los siguientes términos: la posición constitucional de los extranjeros debe debilitarse como mecanismo necesario para desarrollar una política de extranjería con un margen de actuación suficientemente amplio, pues de ello depende una mejor realización de los intereses generales, especialmente los intereses de las personas de nacionalidad española. Por otro lado, la determinación del régimen de extranjería sería uno de los últimos, y principales, atributos de la soberanía estatal. Esto, por tanto, dotaría de sentido la opción de concebir tal régimen en términos de mayor disponibilidad política.

\subsection{Los presupuestos teóricos al descubierto}

La referida jerarquización entre derechos del Tribunal Constitucional responde a una concepción hegemónica de los derechos. Esta concepción, en términos generales, y como tendencia, podría describirse a través de los siguientes ejes:

- Concepción objetiva. Los derechos entendidos como realidades reveladas, abstractas, "objetivas", que el ordenamiento jurídico debe reconocer. Se habla, desde este planteamiento, de la existencia de derechos inherentes a la persona "por el hecho de ser persona".

- Concepción formal. Los derechos se reconocen como elementos de garantía de la igualdad formal, entendida en un plano abstracto, sin incorporar, o haciéndolo de modo limitado, la consideración de las condiciones materiales o posibilidades efectivas de cada sujeto.

- Concepción jerárquica y cronológica o generacional. Se opta por diferenciar jerárquicamente entre los derechos en función de su mayor o menor vinculación a la dignidad de la persona, su mayor o menor "inherencia" a la persona. La consecuencia de la jerarquía es servir de fundamento teórico para las normativas, y para las interpretaciones de las mismas, que establecen distintos grados o intensidades de protección, de efectividad. Esta concepción se apoya en la premisa de que, históricamente, los derechos habrían ido apareciendo y reconociéndose en función, precisamente, de esa graduación: los derechos de primera generación, los derechos civiles y políticos, los derechos económicos, sociales y culturales, como derechos de segunda generación, y otros derechos, "difusos", colectivos y de solidaridad, en tanto que 
derechos de tercera generación. También se apoya en una pretendida distinta naturaleza o estructura: los derechos de primera generación serían derechos de libertad, que conllevan obligaciones meramente omisivas, de no hacer, de no interferencia. En cambio, los derechos sociales serían derechos prestacionales que demandan acciones positivas por parte de los poderes públicos, dependientes por tanto de la disponibilidad financiera y la discrecionalidad política.

- Concepción individual y universal. Los derechos se fundamentan sólo en tanto que mecanismos de garantía de la autonomía individual frente a los demás y frente al Estado. El Estado y el derecho de raíz liberal entienden que las diferencias de tipo cultural, entre otras, deben quedar al margen del debate jurídico, sin salir por tanto de la esfera privada de cada individuo, cuya pertenencia o identidad cultural resulta un dato irrelevante para un Estado que se presenta o bien como culturalmente neutro (acultural) o bien, en algunas versiones, como expresión de una serie de principios universales (transculturales) que no deben ceder frente a ningún particularismo.

\subsection{Una propuesta contrahegemónica}

Frente al "sentido común", dominante, entre sectores críticos y, sobre todo, en la práctica política de numerosas experiencias reivindicativas, los derechos aparecen y dan forma a una concepción que se reclama varias perspectivas.

- Histórica, procesual y subjetiva. Los derechos son entendidos no como realidades reveladas, "objetivas", sino como fruto de procesos de reivindicación y de lucha protagonizados por sujetos concretos, con una especial relevancia de aquéllos que se encuentran en una posición de mayor vulnerabilidad. Los derechos emergen no como fruto de una operación abstracta de reconocimiento de lo ya dado, sino como resultado de una disputa de intereses entre sujetos concretos, cuando aquellos que ven amenazadas sus necesidades logran movilizarse para enfrentar el peligro. Esta concepción tiene la virtud de identificar el conflicto de intereses, las posiciones de poder desigual y, por tanto, situar una disputa que trata de eliminar privilegios para extender derechos.

- Sustancial. Los derechos se entienden desde una perspectiva sustancial, esto es, a partir de las condiciones materiales que permiten su realización y no de un mero reconocimiento formal. Suponen, en consecuencia, la necesidad de que sirvan para atribuir a los sujetos que 
ocupan una posición de mayor vulnerabilidad una serie de recursos concretos, y también de espacios de participación y de autotutela, capaces de garantizar su igualdad sustancial con relación a los demás.

- Indivisible e interdependiente. Todos los derechos, de manera inescindible, forman parte de un cuerpo integral de derechos que comparten las mismas características axiológicas y estructurales. Son derechos, si se quiere, "híbridos", pues todos ellos, cada uno con distintos matices e intensidades, comportan las mismas obligaciones por parte de los poderes públicos y privados: obligaciones tanto de abstención como de prestación, de acción y de omisión, y en parte onerosas y en parte no onerosas. La indivisibilidad, así entendida, se engarza directamente con los principios de interdependencia y de igual jerarquía. La práctica de los derechos constata que difícilmente los derechos pueden entenderse como compartimentos estancos. La efectividad de un derecho redunda en la efectividad del resto; el incumplimiento de un derecho afecta directamente en las condiciones de ejercicio del resto.

- Individual y colectiva. Los derechos se abordan en una doble dimensión individual y colectiva. Se reclama por tanto la necesidad de integrar el contexto grupal donde se encuentran los sujetos, algo que, lejos de establecer una jerarquía entre derechos colectivos e individuales, nos lleva necesariamente al carácter inevitable y complementario de su relación. Se trata, si se quiere, de otra dimensión del carácter sustancial de la comprensión de la igualdad, que pasa por referir los derechos a las condiciones no sólo sociales sino también culturales de los sujetos en el contexto de sociedades desiguales también culturalmente.

\subsection{La igualdad como punto de partida (y de llegada)}

La concepción no jerarquizada de los derechos, como resultado a su vez de una comprensión procesual, sustancial y colectiva, nos aporta una herramienta teórica con la cual fundamentar una dogmática crítica sobre los derechos en general, que resulta aplicable para avanzar en el terreno de la exigibilidad de los derechos sociales, tradicionalmente debilitados.

Pero además se pretende útil para un replanteamiento de la interpretación del régimen de los derechos constitucionales de las personas extranjeras en España. Esta propuesta dogmática propone partir del principio de igualdad como criterio ordenador de la interpretación de todos los derechos, para todos los sujetos. Tal principio, recordemos, tiene como sustentos principales en la 
Constitución de 1978: el artículo 14, que recoge el derecho a no ser discriminado y que cuenta con la máxima protección jurisdiccional (artículo 53.2), y la cláusula de igualación material, contenida en el artículo 9.2, al estilo de la cláusula Basso italiana. Además, la igualdad se considera como uno de los valores superiores del ordenamiento jurídico, recogidos en el artículo 1.1.

Lo que se propone es que, de acuerdo con tales previsiones constitucionales, en el caso de que el legislador considerara necesario diferenciar las condiciones de ejercicio de un derecho, debería, justificar su decisión como excepción al principio de igualdad, a la equiparación de trato que debe tomarse como punto de partida. Este planteamiento, además, por el efecto discursivo y normalizador que tiene el derecho, seguramente serviria para que la igualdad fuese también entendida como punto de llegada, esto es, como aspiración constitucional.

Veamos un ejemplo. Si el legislador pretende establecer un régimen de entrada y permanencia vinculado con determinados criterios referidos a las condiciones del mercado laboral, debe concebirse como una medida que restringe los derechos a la libre circulación (artículo 19) y al trabajo (artículo 35) a partir de un trato desigual respecto de los nacionales. Por esta razón, las medidas adoptadas deben ser necesarias (no existen otras medidas menos lesivas), racionales (adecuación entre fines y medios) y proporcionales (la intensidad de la restricción es adecuada).

Por ello, toda limitación al acceso de personas extranjeras al trabajo que no se halle suficientemente justificada o que resulte desproporcionada respecto del fin perseguido, sería contraria a la Constitución. Con esta óptica debería analizarse el régimen de autorizaciones de residencia y trabajo, análisis del que difícilmente saldrían indemnes muchos de los requisitos exigidos por la legislación de extranjería. ${ }^{10}$ Tratándose además de la restricción de un derecho constitucional, deberá contemplarse rigurosamente la reserva de ley, de manera que el reglamento de ejecución deberá limitarse a ejecutar la ley, sin introducir supuestos no regulados. ${ }^{11}$

\footnotetext{
${ }^{10}$ Los ejemplos son múltiples. Uno de ellos se refiere a la necesidad de acreditar la posesión de un inmueble con capacidad necesaria para el alojamiento de los familiares para los que se solicita el reagrupamiento con antelación a su llegada. Ello implica que la persona solicitante deba realizar un gasto económico meses antes de que, en su caso, sus familiares puedan llegar. También podemos mencionar la exigencia de que el contrato de trabajo con el cual solicitar el visado para obtener la entrada y la residencia en España tenga una duración de un año, cuando actualmente casi ningún contrato inicial alcanza ese tiempo.

${ }^{11}$ Precisamente por vulneración de la reserva de ley fueron considerados nulos diversos preceptos del anterior reglamento de extranjería (Real Decreto 864/2001, de 20 de julio). Concretamente, la sentencia del Tribunal Supremo de 20 de marzo de 2003 consideró nulos un total de quince preceptos. Algunos por directa vulneración de derechos fundamentales. Así por ejemplo, en el fundamento jurídico cuarto de dicha sentencia, el Tribunal Supremo anula el artículo 38 del Reglamento por considerarlo contrario a la libertad de circulación reconocida por el artículo 19.
} 


\section{A modo de epílogo: la libre movilidad como presupuesto}

Podríamos incluso ir más allá en nuestro planteamiento. La igualdad entre nacionales y extranjeros respecto al ejercicio de los derechos no se deriva sólo de que el artículo 13, pese a admitir la posibilidad de regulaciones diferenciadas, establezca la titularidad de los extranjeros de todos los derechos constitucionales (con las excepciones recogidas en el artículo 13.2). Tampoco se vincula sólo a que el principio de igual dignidad sea un eje articulador de todos los derechos del título I. La igualdad parte de un presupuesto anclado en el sistema internacional de los derechos humanos, radicado en la Declaración Universal de 1948. Este sistema pretende ser capaz de garantizar la vigencia de los derechos humanos más allá de la existencia de fronteras territoriales. Por esta razón, se consagra el derecho a la movilidad humana, es decir, el derecho a migrar (emigrar/inmigrar). Lo hace la Declaración Universal de Derechos Humanos (artículo 13.2) y el Pacto Internacional de Derechos Civiles y Políticos de 1966, que en su artículo 12.2 establece:

1. Toda persona que se halle legalmente en el territorio de un Estado tendrá derecho a circular libremente por él y a escoger libremente en él su residencia.

2. Toda persona tendrá derecho a salir libremente de cualquier país, incluso del propio.

3. Los derechos antes mencionados no podrán ser objeto de restricciones salvo cuando éstas se hallen previstas en la ley, sean necesarias para proteger la seguridad nacional, el orden público, la salud o la moral públicas o los derechos y libertades de terceros, y sean compatibles con los demás derechos reconocidos en el presente Pacto.

4. Nadie podrá ser arbitrariamente privado del derecho a entrar en su propio país.

En una estricta interpretación jurídica, del artículo 12.2 deberían extraerse dos obligaciones: la del país de salida a no impedir la salida y la del país de entrada a no rechazar la entrada, en ambos casos con los únicos límites que impone el artículo 12.3. Se deriva, por tanto, que todo control fronterizo, y todo condicionante a la legalidad de la permanencia en un país, resulta una limitación de un derecho y, como tal, en virtud del principio favor libertatis, su alcance debe ser objeto de una aplicación y de una interpretación restrictiva. En otras palabras, a partir del PIDCP, los Estados no pueden considerar el régimen de entrada y permanencia algo sometido a su libre disposición, como último reducto de soberanía, como a menudo pretende ser presentado. 
Existe una observación general que concreta las implicaciones del artículo 12. Se trata de la og 27, aprobada por el Comité de Derechos Humanos de Naciones Unidas en 1999. Sus párrafos 14 y 15 establecen: ${ }^{12}$

14. El párrafo 3 del artículo 12 indica claramente que no basta con que las restricciones se utilicen para conseguir fines permisibles; deben ser necesarias también para protegerlos. Las medidas restrictivas deben ajustarse al principio de proporcionalidad; deben ser adecuadas para desempeñar su función protectora; debe ser el instrumento menos perturbador de los que permitan conseguir el resultado deseado, y deben guardar proporción con el interés que debe protegerse.

15. El principio de proporcionalidad debe respetarse no sólo en la ley que defina las restricciones sino también por las autoridades administrativas y judiciales que la apliquen. Los Estados deben garantizar que todo procedimiento relativo al ejercicio o restricción de esos derechos se lleve a cabo con celeridad y que se expliquen las razones de la aplicación de medidas restrictivas.

Por todo ello, podríamos concluir con la siguiente propuesta. En términos de política legislativa, debe propugnarse la derogación de la Ley de Extranjería. Siendo el punto de partida la igualdad en derechos, las restricciones referidas a personas extranjeras deberian incluirse en las leyes sectoriales concernidas, ámbito por ámbito y debidamente justificadas. Se avanzaría, con ello, en un discurso normativo que evitaría la normalización discursiva de la diferencia, efecto, consciente o no, que produce toda legislación de extranjería.

\footnotetext{
${ }^{12}$ También resulta de enorme interés el conjunto de conductas violatorias especificadas en el párrafo 17, aunque sea redactado referido a las obligaciones del Estado de salida: "Son causa de especial preocupación las múltiples trabas juridicas y burocráticas que afectan innecesariamente el pleno ejercicio de los derechos de las personas a la libre circulación, a salir de un país, incluso del propio, y a adoptar una residencia. [...] En la práctica de los Estados se encuentra una gama todavía más variada de obstáculos que hacen más difícil la salida del pais, sobre todo la de sus propios nacionales. Entre esas normas y prácticas figuran la falta de acceso de los solicitantes a las autoridades competentes y la falta de información sobre los requisitos; la obligación de solicitar formularios especiales para conseguir los documentos oficiales de solicitud de pasaporte; la necesidad de certificados o declaraciones de empleadores o de familiares en apoyo de la solicitud; la descripción exacta del itinerario; la expedición de pasaportes sólo previo pago de tasas elevadas que exceden considerablemente el costo de los servicios prestados por la administración; las demoras injustificadas en la expedición de documentos de viaje; las restricciones a que viajen juntos miembros de la familia; el requisito de depositar una fianza de repatriación o estar en posesión de un billete de vuelta; el requisito de haber recibido una invitación del Estado de destino o de personas que vivan en él; el hostigamiento de los solicitantes, por ejemplo, mediante intimidación física, detención, pérdida del empleo o expulsión de sus hijos de la escuela o la universidad; la negativa a expedir un pasaporte so pretexto de que el solicitante perjudica el buen nombre del pais".
} 
Pero más allá de propósitos legislativos, para concluir debemos insistir en una cuestión: no sólo es necesario, sino también posible y útil proponernos una aproximación crítica a la comprensión del derecho, capaz de develar presupuestos teóricos, analizar su consistencia, mostrar sus incoherencias, proponer otros registros que apunten otras dogmáticas, otra relación entre las palabras y las cosas con la idea de debilitar la consistencia de las condiciones subyacentes de la verdad, esto es, del conjunto de relaciones de poder, en tanto no resultan igualitarias, sino excluyentes. 